\title{
Dietary whey reduces energy intake and alters hypothalamic gene expression in obese phyto-oestrogen-deprived male rats
}

\author{
María F. Andreoli ${ }^{1,2}$, Cora Stoker ${ }^{1,2}$, Gisela P. Lazzarino ${ }^{2}$, Guillermina Canesini ${ }^{2}$, Enrique H. Luque ${ }^{2}$ and \\ Jorge G. Ramos ${ }^{1,2 *}$ \\ ${ }^{1}$ Departamento de Bioquímica Clínica y Cuantitativa, Facultad de Bioquímica y Ciencias Biológicas, Universidad Nacional \\ del Litoral, 3000, Santa Fe, Argentina \\ ${ }^{2}$ Instituto de Salud y Ambiente del Litoral (ISAL), Universidad Nacional del Litoral - Consejo Nacional de Investigaciones \\ Científicas y Técnicas (CONICET), 3000, Santa Fe, Argentina
}

(Submitted 9 May 2016 - Final revision received 29 June 2016 - Accepted 4 July 2016 - First published online 29 July 2016)

\section{Abstract}

Removing dietary phyto-oestrogens in adult male rats causes obesity and diabetes. As whey proteins have been reported to reduce food intake and improve glucose homoeostasis, we investigated whether they could attenuate susceptibility to obesity and diabetes due to phytooestrogen deprivation. To this end, thirty male Wistar rats were fed a high-phyto-oestrogen (HP) or a phyto-oestrogen-free (PF) diet for 10 weeks; six rats from each group were killed. The remaining HP animals (six animals) continued receiving the HP diet for 6 weeks. The remaining PF rats (twelve rats) were divided in two groups: one was given the PF diet and the other a variation of the PF diet plus whey protein (PF-W). Body weight, food intake and adipose tissue weights were recorded. Hypothalamic mRNA expressions of orexigenic (neuropeptide $\mathrm{Y}$, agouti-related protein $(A g R P)$ ) and anorexigenic (pro-opiomelanocortin (POMC), cocaine-amphetamine-related transcript $(C A R T))$ neuropeptides were quantified by real-time PCR. Serum glucose, insulin and total thyroxine (T4), thyroid-stimulating hormone, testosterone and oestradiol were assessed. After 10 weeks of PF diet, increased body weight, adiposity and energy intake, with up-regulation of $A g R P$ and down-regulation of $P O M C$, were observed. Longer treatment exacerbated these results, increased total T4 levels, reduced oestradiol levels and impaired glucose homoeostasis. PF-W reduced energy intake and increased POMC expression; however, body weight and adiposity remained unchanged. PF-W could not prevent the hormonal changes or the high circulating glucose levels induced by phytooestrogen deprivation, but reduced fasting insulin. These data demonstrate that, although 6 weeks of whey administration could not prevent obesity in phyto-oestrogen-deprived rats, the reduction in energy intake and circulating insulin could be beneficial with longer treatments.

Key words: Whey: Obesity: Hypothalamus: Phyto-oestrogens

Phyto-oestrogens are non-steroidal compounds found in many legumes and are particularly abundant in soya products. They have been reported to have a beneficial effect on body weight and adipose tissue deposition, mainly in postmenopausal women $^{(1,2)}$. Our group has recently reported that removing phyto-oestrogens from the diet of male adult rats induces obesity and diabetes, increasing energy intake through an orexigenic hypothalamic response mediated by neuropeptides $^{(3)}$. The arcuate nucleus in the hypothalamus is the central area involved in the control of food intake ${ }^{(4,5)}$. This nucleus contains two distinct populations of neurons: one produces orexigenic neuropeptides such as agouti-related protein (AgRP) and neuropeptide Y (NPY), whereas the other synthesises anorexigenic substances such as cocaine-amphetamine-related transcript (CART) and pro-opiomelanocortin (POMC) $)^{(4,5)}$

The obesity pandemic can be prevented and managed by means of different dietary manipulations. At present, energy restriction is one of the most effective ways for individuals with obesity to lose weight and ameliorate-related metabolic diseases. Moreover, altering the macronutrient composition of the diet may be an effective way to improve food intake regulation and induce satiety.

Different protein types affect body weight and food intake: dairy proteins are known to suppress short-term food intake, increase subjective satiety and stimulate the mechanisms known to signal satiety ${ }^{(6)}$. However, the contribution of major

Abbreviations: AgRP, agouti-related protein; CART, cocaine-amphetamines-related transcript; $\mathrm{E}_{2}$, oestradiol; HOMA, homoeostasis model assessment. HP, high phyto-oestrogen; HP-10 wk, high-phyto-oestrogen diet administered for 10 weeks; HP-16 wk, high-phyto-oestrogen diet administered for 16 weeks; PF, phyto-oestrogen-free diet; PF-10 wk, phyto-oestrogen-free diet administered for 10 weeks; PF-16 wk, phyto-oestrogen-free diet administered for 16 weeks; $\mathrm{PF}-\mathrm{W}$, phyto-oestrogen-free diet containing whey; POMC, pro-opiomelanocortin; T4, thyroxine.

* Corresponding author: J. G. Ramos, fax +54342 4510283, email gramos@fbcb.unl.edu.ar 
protein fractions such as whey to the control of food intake and the peripheral and central mechanisms involved have received little attention.

As whey protein is an abundant by-product in cheese production (10 litres of milk produces about 9 litres of whey during cheese manufacturing), it is considered an inexpensive source of high-quality protein that can be used in functional foods claiming health benefits ${ }^{(7)}$. Several studies conducted in humans have shown that whey supplementation affects appetite and reduces food intake ${ }^{(8-10)}$. However, it is unclear whether the consumption of whey affects the central mechanisms involved in food intake control. Animal studies assessing how whey protein affects food intake have used different experimental models with diverse amounts of dietary proteins ${ }^{(11-14)}$, as well as diverse experimental procedures (duration of the treatment, protein content, use of protein preloads, age and sex of the subjects, etc.), which make it difficult to draw a definitive conclusion about the effects of whey on appetite. Thus, further studies are needed to clarify the role of whey protein in the central control of energy intake.

Whey proteins have been demonstrated to improve glucose homoeostasis and insulin sensitivity in both rodent models and humans ${ }^{(15-17)}$. In addition, whey proteins have been reported to diminish postprandial glycaemia ${ }^{(18,19)}$ through various interrelated mechanisms including enhancement of insulin and release of incretins ${ }^{(15,20)}$. These properties of whey proteins suggest that they can be used for the management of diabetes induced by different dietary treatments.

Given the possible beneficial effects of whey for overweight individuals, the aim of the present study was to evaluate whether a diet supplemented with whey protein concentrate can attenuate the susceptibility to obesity and diabetes in adult male rats previously exposed to a phyto-oestrogen-free (PF) diet, preventing or reversing alterations in central mechanisms of energy intake control. We consider that assessing the potential beneficial effects of whey intake on hyperphagic obese individuals would be relevant as whey could interfere in the obesogenic mechanisms of action of phyto-oestrogen deprivation.

\section{Methods}

\section{Preparation of diets}

The composition of diets was based on the American Institute of Nutrition Ad Hoc Committee recommendation for adult rodents $\left(\right.$ AIN-93M) ${ }^{(21)}$ and is shown in Table 1. All diets were prepared inhouse using AIN 93 mineral and vitamin mixes, choline chloride, DL-methionine and $\alpha$-cellulose from MP Biomedicals and using local sources of feed-grade sucrose, maize starch, soyabean oil and casein. A high-phyto-oestrogen (HP) diet was prepared with the addition of genistein and daidzein (Indofine Chemical Company). The amounts of phyto-oestrogens added were chosen to match those present in the regular laboratory chow previously used by our group ${ }^{(3)}$. The PF was identical to the HP diet but without the addition of genistein and daidzein. The PF containing whey protein (PF-W) diet was a variation of the PF diet and contained whey protein concentrate instead of casein as a source of dietary protein. Whey protein concentrate (Lacprodan 80) was
Table 1. Composition of the experimental diets

\begin{tabular}{lccc}
\hline Ingredients & HP & PF & PF-W \\
\hline Maize starch $(\mathrm{g} / \mathrm{kg})$ & 621.5 & 621.5 & 621.5 \\
Casein $(\mathrm{g} / \mathrm{kg})$ & 140 & 140 & - \\
Whey protein concentrate $(\mathrm{g} / \mathrm{kg})$ & - & - & 140 \\
Sucrose $(\mathrm{g} / \mathrm{kg})$ & 100 & 100 & 100 \\
Soyabean oil $(\mathrm{g} / \mathrm{kg})$ & 40 & 40 & 40 \\
a-Cellulose $(\mathrm{g} / \mathrm{kg})$ & 50 & 50 & 50 \\
AIN 93 mineral mix (g/kg) & 35 & 35 & 35 \\
AIN 93 vitamin mix (g/kg) & 10 & 10 & 10 \\
DL-Met (g/kg) & 3.0 & 3.0 & 3.0 \\
Choline chloride (g/kg) & 1.5 & 1.5 & 1.5 \\
Genistein (mg/kg) & 190 & - & - \\
Daidzein (mg/kg) & 210 & - & - \\
Energy content (J/g) & 15072 & 15072 & 15072 \\
\hline HP, high-phyto-oestrogen; PF, phyto-oestrogen-free; PF-W, PF diet supplemented \\
$\quad$ with whey.
\end{tabular}

kindly provided by Arla Foods Ingredients. The three diets were isoenergetic, as can be seen in Table 1. The levels of phyto-oestrogens were quantified in the HP diet, and their absence in the PF and PF-W diets was confirmed using HPLC analysis.

\section{Animals and general protocol}

All the procedures were approved by the Ethics Committee of the School of Biochemistry and Biological Sciences (University of Litoral), and were performed in accordance with the principles and procedures outlined in the Guide for the Care and Use of Laboratory Animals issued by the US National Academy of Sciences ${ }^{(22)}$. In all, thirty adult male Wistar rats were obtained from the Department of Human Physiology (University of Litoral). From conception until the beginning of the experiment, rats were housed under controlled conditions $\left(23 \pm 2^{\circ} \mathrm{C}\right.$ and $12 \mathrm{~h}$ light $-12 \mathrm{~h}$ dark cycle) with free access to the HP diet. When the animals reached a weight of 250-300 g, they were randomly divided into two weight-matched groups and subjected to the following dietary treatments for 10 weeks. One group ( $n$ 12) was used as control and had ad libitum access to the same HP diet administered for 10 weeks (HP-10-wk group). To evaluate the effects of withdrawing phyto-oestrogens from the diet, the other group ( $n$ 18) was fed the PF diet administered for 10 weeks (PF-10-wk group). Body weight was recorded at the beginning and at the end of the experiment. Food intake was measured daily during the experimental period, calculating the weight difference between the offered and remaining food, adjusted for wastage by calculating food spillage. Energy intake was calculated by multiplying the amounts of ingested food with the respective energy contents. At the end of this treatment, six rats from each group were euthanised by decapitation. Trunk blood was collected, samples were centrifuged and serum was immediately used or frozen and stored at $-80^{\circ} \mathrm{C}$ until analysis. Epididymal and perirenal fat pads were dissected and weighed. Immediately after euthanasia, the brain was removed from the skull, and the medio-basal hypothalamus was dissected (according to Paxinos atlas coordinates -1.0 to $-4.5 \mathrm{~mm}$ from Bregma and $3 \mathrm{~mm}$ in depth) ${ }^{(23)}$, snap-frozen in liquid $\mathrm{N}_{2}$ and stored at $-80^{\circ} \mathrm{C}$ until RNA isolation. 
The remaining HP animals (six animals) continued receiving the HP diet administered for 16 weeks (HP-16 wk group), whereas the remaining $\mathrm{PF}$ rats (twelve rats) were divided into two groups (six rats each): one group was fed the PF diet administered for 16 weeks (PF-16wk), and the other group received the $\mathrm{PF}-\mathrm{W}$ diet to assess whether whey proteins could prevent or reverse the effects of phyto-oestrogen deprivation. Body weight and energy intake were also recorded in this period. At the end of the dietary treatments, the animals were euthanised and samples were collected as described above.

\section{RNA isolation, reverse transcription and real-time quantitative $P C R$}

Total RNA was isolated from the hypothalamus using TRIzol (Invitrogen) according to the manufacturer's protocol. Reverse transcription and real-time quantitative PCR were performed as previously described using specific primer pairs for ribosomal protein $L 19$ (housekeeping gene), Agrp, Pomc, Cart and $N p y^{(3)}$. In brief, real-time quantitative PCR was carried out using a SYBR Green PCR master mix (HOTFIREPol EvaGreen qPCR Mix Plus (Solis BioDyne, Biocientífica)) and a real-time PCR system StepOne Cycler (Applied Biosystems Inc., Life Technologies). Product purity was confirmed by dissociation curves, and random samples were subjected to agarose gel electrophoresis. All reactions were carried out at least in triplicate. Fold change from HP values was determined using the delta-delta $C_{t}$ method $^{(24)}$.

\section{Circulating glucose and hormone measurements}

Fasting glucose was measured using commercially available kits (Wiener Lab). Serum insulin was assessed by RIA using an anti-rat insulin antibody (Sigma) and standard rat insulin provided by Laboratorios Beta. Thyroid-stimulating hormone was determined by competitive RIA according to the procedure outlined by Catalano et $a l^{(25)}$ The levels of total thyroxine (T4), oestradiol $\left(\mathrm{E}_{2}\right)$ and testosterone were measured using competitive RIA kits (Immunotech). Insulin resistance was evaluated according to the homoeostasis model assessment (HOMA). The HOMA index was calculated as (fasting insulin $(\mathrm{IU} / \mathrm{ml}) \times$ fasting glucose $(\mathrm{mol} / \mathrm{l})) / 22 \cdot 5^{(26)}$.

\section{Statistical analysis}

Data corresponding to the HP-10-wk and PF-10-wk groups (expressed as means with their standard errors) were statistically analysed by Student's $t$ test. Data from the HP-16 wk, PF-16-wk and PF-W groups (also expressed as means with their standard errors) were analysed by one-way ANOVA. Post boc multiple comparisons were made using Tukey's critical range test. In all cases, differences were considered significant at $P<0 \cdot 05$. For all the analyses, IBM SPSS Statistics 19 software (IBM Inc.) was used.

\section{Results}

Effects of 10 weeks of phyto-oestrogen deprivation

Phyto-oestrogen deprivation increased adipose tissue, body weight and energy intake. Rats fed the PF diet for 10 weeks
Table 2. Final body and adipose tissue weights and food and energy intake in animals fed high-phyto-oestrogen (HP) or phyto-oestrogen-free (PF) diet for 10 weeks

(Mean values with their standard errors, $n 6$ )

\begin{tabular}{|c|c|c|c|c|}
\hline & \multicolumn{2}{|c|}{$\mathrm{HP}-10 \mathrm{wk}$} & \multicolumn{2}{|c|}{ PF-10wk } \\
\hline & Mean & SEM & Mean & SEM \\
\hline $\begin{array}{l}\text { Final body weight } \\
\text { Epididymal fat pads weight }\end{array}$ & 364 & 9 & $426^{*}$ & 11 \\
\hline $\begin{array}{l}\mathrm{g} \\
\mathrm{g} / 100 \mathrm{~g} \text { of Body weight }\end{array}$ & $\begin{array}{l}9 \cdot 14 \\
2 \cdot 49\end{array}$ & $\begin{array}{l}0.41 \\
0.10\end{array}$ & $\begin{array}{r}17.03^{*} \\
4.05^{*}\end{array}$ & $\begin{array}{l}1.05 \\
0 \cdot 15\end{array}$ \\
\hline Perirenal fat pads weight & & & & \\
\hline $\begin{array}{l}\mathrm{g} \\
\mathrm{g} / 100 \mathrm{~g} \text { of Body weight }\end{array}$ & $\begin{array}{l}9.44 \\
2.58\end{array}$ & $\begin{array}{l}0.68 \\
0.17\end{array}$ & $\begin{array}{r}19 \cdot 57^{*} \\
4 \cdot 65^{\star}\end{array}$ & $\begin{array}{l}1.43 \\
0.23\end{array}$ \\
\hline Food intake $(\mathrm{g} / \mathrm{d})$ & $15 \cdot 68$ & 0.26 & $22 \cdot 26^{\star}$ & 0.34 \\
\hline Energy intake (kJ/d) & 221.4 & $3 \cdot 84$ & $335 \cdot 5^{\star}$ & $5 \cdot 1$ \\
\hline
\end{tabular}

HP-10 wk, HP diet administered for 10 weeks; PF-10wk, PF diet administered for 10 weeks.

* Significant differences at $P<0.001$ (Student's $t$ test).

significantly increased their body weights (+17\%) (Table 2$)$. To determine whether there was a region-specific fat gain, selected fat deposits (epididymal and perirenal) were excised and weighed. Consistent with the changes in body weight, PF-10-wk animals had significantly greater amounts of epididymal and perirenal fat than HP-10-wk rats, expressed both in grams (absolute value) and as a percentage of body weight (Table 2). In close relation to this, food intake in animals fed the PF diet for 10 weeks was increased. This hyperphagia led to a significant increase in average energy intake compared with the HP-10-wk group (Table 2). Energy intake was higher in PF-10-wk $v$. HP-10-wk animals throughout the experiment, as can be seen in Fig. 1.

Increased energy intake was associated with changes in the hypothalamic expressions of neuropeptides. In rats, 10 weeks of phyto-oestrogen deprivation induced an orexigenic response by significantly reducing anorexigenic $P O M C$ mRNA expression, increasing orexigenic $A g R P$ and concomitantly decreasing $N P Y$ expression, as compared with the HP-10-wk group $(P<0 \cdot 05)$. CART mRNA levels were unchanged (Fig. 2).

10 Weeks of phyto-oestrogen deprivation did not affect glucose metabolism. Phyto-oestrogen deprivation did not affect fasting glucose, insulin or the HOMA index (Table 3).

\section{Effects of whey administration}

Whey administration reduced food and energy intake but did not affect adipose tissue or body weight. When the animals continued receiving the PF for 6 more weeks, their body weights remained higher compared with HP-fed rats. This was reflected in the final body weight (Table 4). PF-W rats showed a slight reduction in their final body weight that did not reach statistical significance $v$. PF-16-wk rats. Fat accretion observed in rats deprived of phyto-oestrogens for 10 weeks was exacerbated: compared with HP-16-wk rats, PF-16-wk rats had significantly greater amounts of epididymal $(+50 \%)$ and perirenal (+60\%) fat (Table 4). Consistent with the lack of changes 


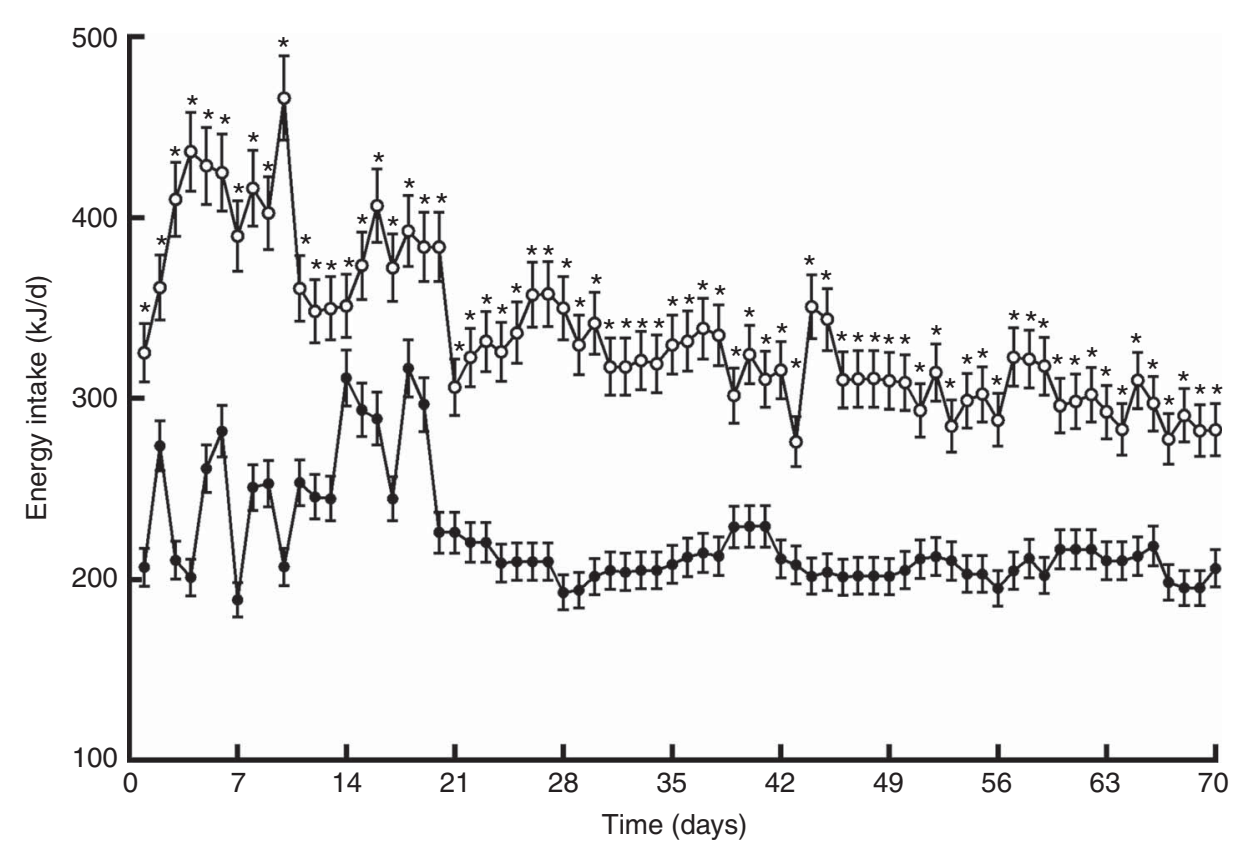

Fig. 1. Energy intake of rats fed high-phyto-oestrogen (HP-10 wk, $-\longrightarrow)$ or phyto-oestrogen-free (PF-10 wk, $\multimap-$ ) diets for 10 weeks. Data shown are presented as means $(n 6)$, with their standard errors. ${ }^{\star}$ Significant differences at $P<0.05$ (Student's $t$ test).
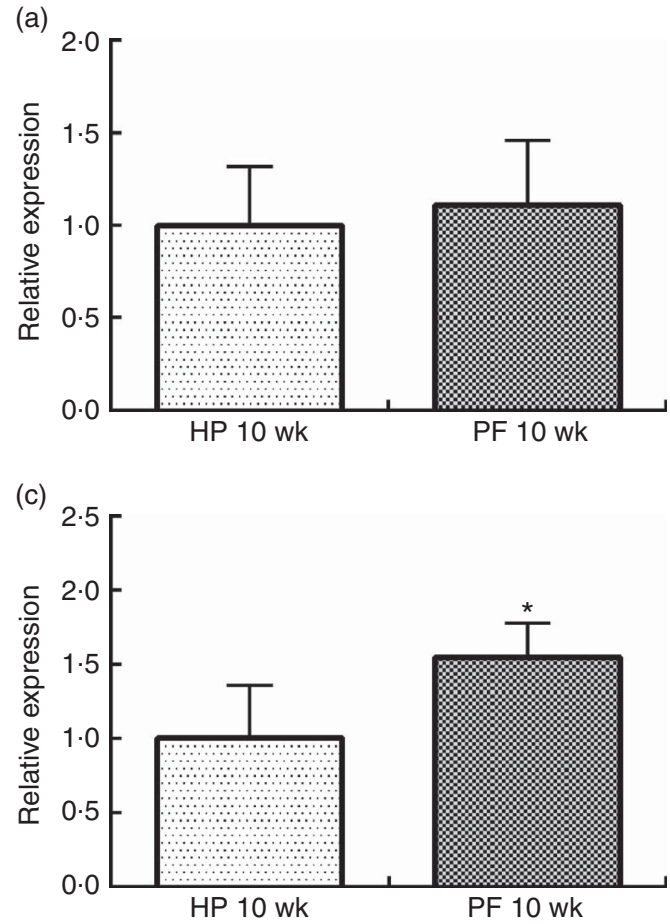
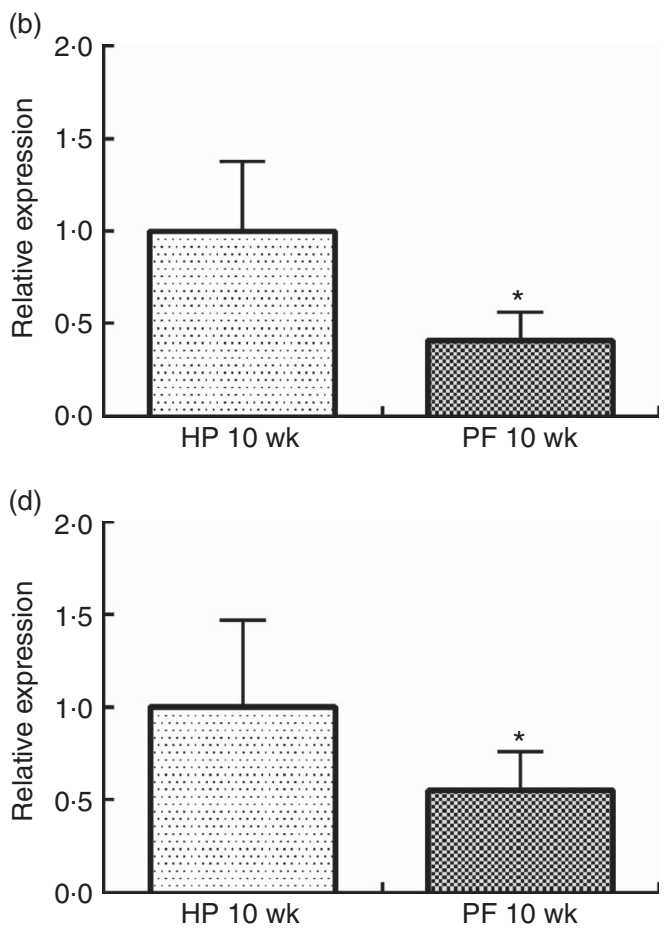

Fig. 2. Hypothalamic expression of (a) cocaine-amphetamine-related transcript, (b) pro-opiomelanocortin, (c) agouti-related protein and (d) neuropeptide $Y$ in rats fed high-phyto-oestrogen (HP-10 wk) or phyto-oestrogen-free (PF-10 wk) diets for 10 weeks. Relative RNA expression was measured by quantitative real-time RT-PCR and is expressed as fold change from HP 10-wk values. Expression was normalised to that of ribosomal protein L19. Data shown are presented as means ( $n 6)$, with their standard errors. ${ }^{\star}$ Significant differences at $P<0.05$ (Student's $t$ test).

in body weight, PF-W rats showed no changes in fat deposit weight (Table 4). As seen in the 10-week treatment, PF-16-wk rats were hyperphagic, and 6 weeks of whey administration reduced food and energy intake by $16 \%$ (Table 4). This reduction was noticeable around day 10 of diet exposure, and remained until the end of the study (Fig. 3). 
The reduction in energy intake was associated with changes in the hypothalamic expression of neuropeptides. In line with the results observed in animals that were treated for 10 weeks, PF-16-wk rats showed an orexigenic response with reduced $P O M C$ and increased $A g R P$ expression $v$. the HP-16-wk group $(P<0.001)$ (Fig. 4). Nevertheless, $N P Y$ and $C A R T$ mRNA levels were unchanged. The reduced energy intake observed in PF-W rats with respect to PF-16-wk rats was linked to an increase in $P O M C$ mRNA levels $(P<0 \cdot 001)$, although $A g R P$ expression remained similar to that in PF-16-wk animals $(P<0 \cdot 001)$ (Fig. 2).

Whey administration did not prevent hormonal changes induced by phyto-oestrogen deprivation. The blood hormone profile of the animals is shown in Table 5; 16 weeks of phytooestrogen deprivation increased the levels of total $\mathrm{T} 4$ and reduced levels of $\mathrm{E}_{2}$ compared with the HP-16-wk group. Whey administration did not prevent these changes. Thyroid-stimulating hormone and testosterone levels were not affected by the treatment.

\section{Whey administration did not improve glucose metabolism} impaired by 16 weeks of phyto-oestrogen deprivation. In this study, 16 weeks of phyto-oestrogen deprivation increased fasting blood glucose and insulin levels, leading to a higher HOMA index (Table 6), indicating insulin resistance. PF-W rats showed similar fasting glucose and reduced insulin concentrations ( $v$. PF-16-wk rats), although this reduction was not sufficient to affect the HOMA index ( $v$. PF-16-wk rats).

Table 3. Glucose metabolism parameters in animals-fed highphyto-oestrogen (HP) or phyto-oestrogen-free (PF) diet for 10 weeks (Mean values with their standard errors, $n 6$ )

\begin{tabular}{lrrrrr}
\hline & \multicolumn{2}{c}{ HP-10wk } & & \multicolumn{2}{c}{ PF-10 wk } \\
\cline { 2 - 3 } \cline { 6 - 7 } & Mean & SEM & & Mean & SEM \\
\hline Insulin (mU/l) & 31.12 & 3.05 & & 35.50 & 4.72 \\
Fasting glucose (mM) & 5.86 & 0.29 & & 6.10 & 0.35 \\
HOMA & 8.16 & 0.93 & & 9.52 & 1.13 \\
\hline
\end{tabular}

HP-10 wk, HP diet administered for 10 weeks; PF-10 wk, PF diet administered for 10 weeks; HOMA, homoeostasis model assessment.

\section{Discussion}

This study demonstrates for the first time that obese phyto-oestrogen-deprived male rats fed whey display a food intake reduction and an alteration in the gene expressions of food intake-regulating hypothalamic neuropeptides. However, the dietary treatment with whey for 6 weeks was unable to prevent obesity induced by phyto-oestrogen deprivation in the adult stage of life. We consider that this rat model is suitable for the study of human obesity, because it evaluates the effects of whey in obese individuals, when energy intake is increased and hypothalamic neuropeptides are already altered, reflecting an actual background of chronic obesity.

We have recently reported that if male rats consume phytooestrogens until they reach adult life, and if the feed is replaced by a PF diet, rats develop an obese phenotype with diabetes and alterations in energy intake mediated by a hypothalamic orexigenic neuropeptide response. These results were achieved with a 15 -week dietary treatment ${ }^{(3)}$. We now showed that 10 weeks of phyto-oestrogen deprivation is enough to cause obesity with increased adiposity and body weight, but not to induce diabetes. Replacing the HP diet by a PF diet resulted in obesity due to an anabolic process, with changes in food intake mediating the weight gain at least in part. However, we cannot rule out that alteration in other mechanisms such as energy expenditure may also be involved. As previously seen ${ }^{(3)}$, hypothalamic neuropeptide signals mediate this process; phytooestrogen deprivation for 10 weeks significantly decreased $P O M C$ and increased $A g R P$ mRNA, implying that energy intake is increased at least partially through these systems. Regarding the paradoxical increase in $N P Y$ gene expression, it has been reported that the Agrp/Npy neurons primarily sense energy deficits, whereas the Pomc/Cart neurons primarily sense energy excess, as reported by Barsh \& Schwartz ${ }^{(27)}$. These authors also indicated that $N P y$ mRNA levels are up-regulated by starvation but are not always affected by energy excess.

The current results on the effects of 10 or 16 weeks of phytooestrogen deprivation in adult male rats were obtained by feeding animals a semi-synthetic AIN-based diet. The formulation of this diet made possible to manipulate the macronutrient composition, allowing the replacement of casein (the source of

Table 4. Final body and adipose tissue weights and food and energy intake in animals-fed high-phyto-oestrogen (HP) diet, phyto-oestrogen-free (PF) diet or PF diet supplemented with whey (PF-W)

(Mean values with their standard errors, $n 6$ )

\begin{tabular}{|c|c|c|c|c|c|c|}
\hline & \multicolumn{2}{|c|}{ HP-16 wk } & \multicolumn{2}{|c|}{ PF-16 wk } & \multicolumn{2}{|c|}{ PF-W } \\
\hline & Mean & SEM & Mean & SEM & Mean & SEM \\
\hline $\begin{array}{l}\text { Final body weight } \\
\text { Epididymal fat pads weight }\end{array}$ & $459^{\mathrm{a}}$ & 6 & $484^{b}$ & 5 & $469^{a, b}$ & 6 \\
\hline $\begin{array}{l}\mathrm{g} \\
\mathrm{g} / 100 \mathrm{~g} \text { of Body weight }\end{array}$ & $\begin{array}{r}14 \cdot 22^{\mathrm{a}} \\
2 \cdot 86^{\mathrm{a}}\end{array}$ & $\begin{array}{l}0.66 \\
0.15\end{array}$ & $\begin{array}{r}21.66^{\mathrm{b}} \\
4.52^{\mathrm{b}}\end{array}$ & $\begin{array}{l}0.44 \\
0.09\end{array}$ & $\begin{array}{r}20 \cdot 05^{\mathrm{b}} \\
4.40^{\mathrm{b}}\end{array}$ & $\begin{array}{l}0.93 \\
0.12\end{array}$ \\
\hline Perirenal fat pads weight & & & & & & \\
\hline $\begin{array}{l}\mathrm{g} \\
\mathrm{g} / 100 \mathrm{~g} \text { of Body weight }\end{array}$ & $\begin{array}{r}14.66^{\mathrm{a}} \\
3.86^{\mathrm{a}}\end{array}$ & $\begin{array}{l}1.07 \\
0.18\end{array}$ & $\begin{array}{r}26 \cdot 66^{\mathrm{b}} \\
5.46^{\mathrm{b}}\end{array}$ & $\begin{array}{l}0.48 \\
0.07\end{array}$ & $\begin{array}{r}24 \cdot 21^{\mathrm{b}} \\
5 \cdot 28^{\mathrm{b}}\end{array}$ & $\begin{array}{l}1 \cdot 18 \\
0 \cdot 16\end{array}$ \\
\hline Food intake $(\mathrm{g} / \mathrm{d})$ & $15 \cdot 11^{\mathrm{a}}$ & 0.13 & $22 \cdot 17^{\mathrm{b}}$ & 0.31 & $18.48^{\mathrm{C}}$ & 0.25 \\
\hline Energy intake (kJ/d) & $215^{a}$ & 2 & $334^{b}$ & 5 & $279^{c}$ & 4 \\
\hline
\end{tabular}

HP-16 wk, HP diet administered for 16 weeks; PF-16wk, PF diet administered for 16 weeks.

a,b,c Mean values within a row with unlike superscript letters were significantly different at $P<0.05$ (Tukey's test after one-way ANOVA). 
dietary proteins recommended by the American Institute of Nutrition for rodent diets ${ }^{(21)}$ ) by whey protein concentrates to assess their potential beneficial effects. The amount of phytooestrogens added to obtain the HP diet was similar to that present in regular laboratory chow, in which soya is used as the main source of protein ${ }^{(28)}$.

Feeding the PF diet for 16 weeks exacerbated the accretion of fat tissue and the body weight gain observed in animals treated for 10 weeks. Hyperphagia and excessive energy intake also

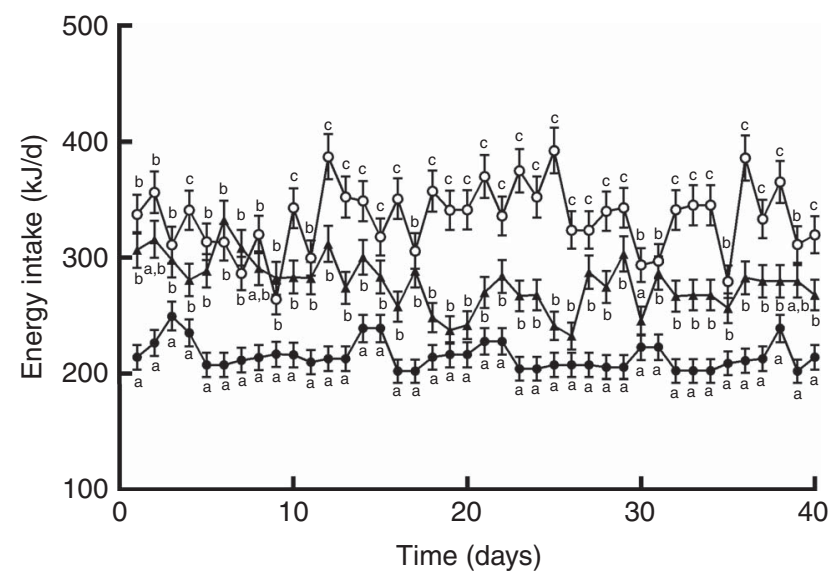

Fig. 3. Energy intake of rats fed high-phyto-oestrogen (HP-16wk, —phyto-oestrogen-free (PF-16 wk, - - $)$ or phyto-oestrogen-free + whey (PF-W, — - diets. Data shown are presented as means $(n 6)$, with their standard errors. ${ }^{\mathrm{a}, \mathrm{b}, \mathrm{c}}$ Unlike letters indicate significant differences $(P<0.05$ by Tukey's test after one-way ANOVA).
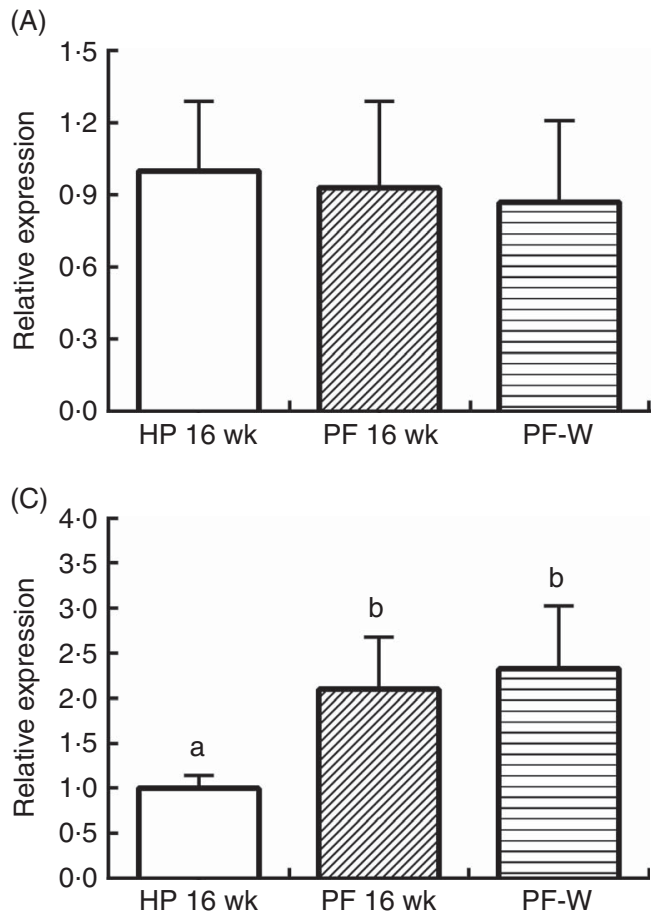

persisted, but with the same magnitude as that observed in PF-10-wk $v$. HP-10-wk rats. However, orexigenic hypothalamic signalling was more prominent: $A g R P$ mRNA expression was 1.55-fold higher in PF-10-wk rats than in HP-10-wk rats and 2.1fold higher in PF-16-wk rats than in HP-16-wk rats. These results show that as the dietary treatment progresses, $A g R P$ expression increases to maintain the hyperphagic behaviour.

The switch to PF diet in adulthood generates obesity and glucose homoeostasis impairment. In this study, we aimed to investigate whether these effects could be attenuated using whey as a source of dietary protein, as it has numerous wellknown health benefits. We observed that whey administration for 6 weeks was not enough to affect body weight or epididymal or perirenal fat pad weight. Zhou et al. ${ }^{(12)}$ reported that whey administration reduced body fat and body weight gain in Sprague-Dawley rats, but the dietary treatment was longer (10 weeks) and whey was provided in the context of a highprotein diet, which is known to promote weight loss ${ }^{(29)}$. Pezeshki et al. ${ }^{(14)}$ showed that whey significantly reduced fat mass in obese rats, but the animals were obesity-prone rats previously fed a high-fat diet. These authors also reported that whey reduced energy expenditure in these animals, indicating that this mechanism plays a role in the anti-obesity effect of whey proteins. Therefore, the strain of the animals, their preceding obese or lean status, the amount of dietary proteins and the duration of the experimental protocol may affect the ability of whey to alter body weight and adiposity. Besides, the number of animals in each group in our study could have been insufficient to reach statistical significance for the parameters evaluated.

(B)
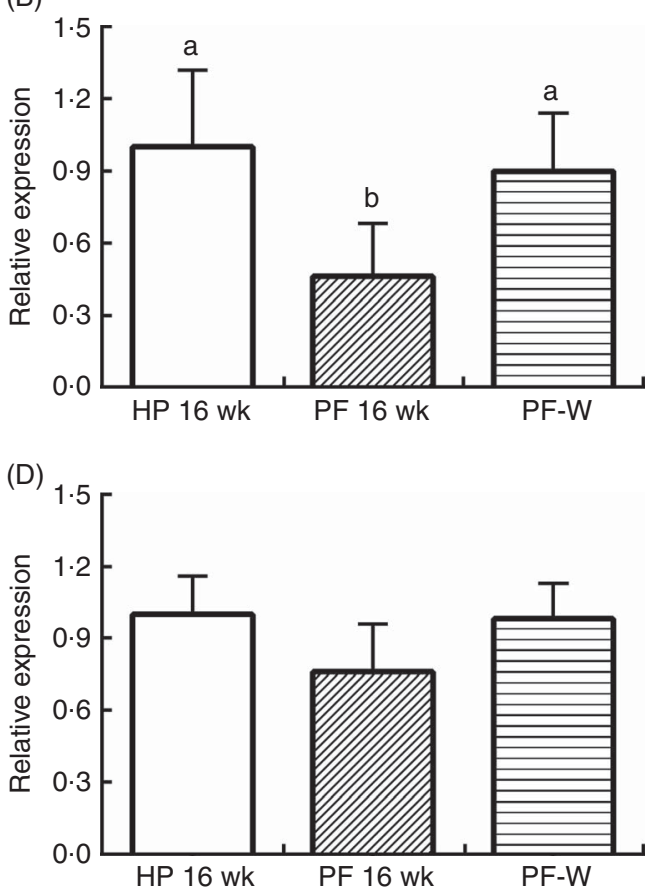

Fig. 4. Hypothalamic expression of (A) cocaine-amphetamine-related transcript, (B) pro-opiomelanocortin, (C) agouti-related protein and (D) neuropeptide $Y$ in rats fed high-phyto-oestrogen (HP-16 wk), phyto-oestrogen-free (PF-16 wk) or phyto-oestrogen-free + whey (PF-W) diets. Relative RNA expression was measured by quantitative real-time RT-PCR and is expressed as fold change from HP-16 wk values. Expression was normalised to that of ribosomal protein L19. Data shown are presented as means $(n 6)$, with their standard errors. ${ }^{\text {a,b }}$ Mean values with unlike letters were significantly different at $P<0.05$ (Tukey's test after one-way ANOVA). 
Table 5. Blood hormones in animals fed high-phyto-oestrogen (HP) diet, phyto-oestrogen-free (HP) diet or PF diet supplemented with whey (PF-W)

(Mean values with their standard errors, $n 6$ )

\begin{tabular}{|c|c|c|c|c|c|c|}
\hline & \multicolumn{2}{|c|}{$\mathrm{HP}-16$ wk } & \multicolumn{2}{|c|}{ PF-16 wk } & \multicolumn{2}{|c|}{ PF-W } \\
\hline & Mean & SEM & Mean & SEM & Mean & SEM \\
\hline \multicolumn{7}{|l|}{ Thyroid system hormones } \\
\hline Total thyroxine $(\mathrm{nmol} / \mathrm{l})$ & $21 \cdot 16^{\mathrm{a}}$ & 1.43 & $41 \cdot 22^{\mathrm{b}}$ & 1.29 & $44 \cdot 98^{b}$ & 2.44 \\
\hline Thyroid-stimulating hormone (ng/ml) & 3.67 & 0.45 & $2 \cdot 78$ & 0.35 & $2 \cdot 51$ & 0.40 \\
\hline \multicolumn{7}{|l|}{ Sex hormones } \\
\hline Testosterone (ng/ml) & 1.08 & 0.22 & 0.48 & 0.08 & 1.09 & 0.27 \\
\hline Oestradiol $(\mathrm{pg} / \mathrm{ml})$ & $5.44^{\mathrm{a}}$ & 0.41 & $2 \cdot 15^{\mathrm{b}}$ & 0.53 & $1 \cdot 12$ & 0.36 \\
\hline
\end{tabular}

Table 6. Glucose metabolism parameters in animals in animals fed high-phyto-oestrogen (HP) diet, phyto-oestrogen-free (PF) diet or PF diet supplemented with whey (PF-W)

(Mean values with their standard errors, $n 6$ )

\begin{tabular}{|c|c|c|c|c|c|c|}
\hline & \multicolumn{2}{|c|}{$\mathrm{HP}-16$ wk } & \multicolumn{2}{|c|}{ PF-16 wk } & \multicolumn{2}{|c|}{ PF-W } \\
\hline & Mean & SEM & Mean & SEM & Mean & SEM \\
\hline Insulin (mU/l) & $29.88^{a}$ & 0.86 & $43.67^{b}$ & 0.99 & $35 \cdot 81^{c}$ & 2.51 \\
\hline Fasting glucose $(\mathrm{mM})$ & $5 \cdot 21^{\mathrm{a}}$ & 0.24 & $7 \cdot 76^{b}$ & 0.13 & $8.58^{b}$ & 0.23 \\
\hline HOMA & $6 \cdot 49^{\mathrm{a}}$ & 0.36 & $14 \cdot 78^{\mathrm{b}}$ & 0.49 & $13.55^{\mathrm{b}}$ & $0.75^{\mathrm{b}}$ \\
\hline
\end{tabular}

HP-16 wk, HP diet administered for 16 weeks; PF-16 wk, PF diet administered for 16 weeks; HOMA, homoeostasis model assessment. a,b,c Mean values within a row with unlike superscript letters were significantly different at $P<0.05$ (Tukey's test after one-way ANOVA).

Our results show that whey administration significantly reduced food and energy intake. This was associated with an increase in the anorexigenic signal of $P O M C$, although $A g R P$ expression remained unchanged compared with PF-16-wk animals. It was also noticeable that energy intake in PF-W remained higher than in HP animals. This could suggest involvement of other neuropeptides such as orexins or changes in hedonic mechanisms of food intake control. The greater satiating effect of whey protein is in agreement with results by other authors $^{(10,11,30)}$; however, the mechanisms involved in food intake are still unknown. Pezeshki et al. ${ }^{(14)}$ showed that the satiating effect was related to a reduction in taste preference. Hall et $a l^{(30)}$, reported an increased satiety response to whey with respect to casein in human subjects and stated that this response was mediated by plasma amino acids and gastrointestinal hormones. The influx of amino acids following ingestion of whey proteins is also an important factor in the effect of whey on food intake. It is widely known that different amino acids and proteins affect peripheral and central mechanisms involved in food intake control ${ }^{(31)}$. Whey proteins contain a high concentration of branched-chain amino acids ${ }^{(32)}$, with L-leucine representing about $10 \%$ of the total amino acids of whey ${ }^{(7)}$. The importance of leucine in the hypothalamic food intake regulatory system has been reported, as its intracerebroventricular injection has been shown to suppress food intake. This effect has been related to increased mammalian target of rapamycin (mTOR) activity in the hypothalamus, which leads to the stimulation of $P O M C$ expression ${ }^{(33)}$, in agreement with our results.

It has been previously reported that phyto-oestrogen deprivation modifies endocrine homoeostasis ${ }^{(3,34,35)}$. Phyto-oestrogen-deprived rats showed higher circulating total
T4 and slightly (but not significant) decreased thyroidstimulating hormone, probably as a consequence of negative feedback from T4. Other authors have reported that phyto-oestrogens, particularly genistein, reduce circulating thyroid hormone levels, as they affect their synthesis, metabolism and thyroid hormone transport proteins ${ }^{(36)}$. In our study, the presence of whey in the diet was unable to prevent these alterations. The potential effects of whey on the thyroid system remain unknown. It has been recently reported that 36 weeks of treatment with whey did not interfere with thyroid status in overweight human subjects $^{(37)}$, in agreement with our results.

A plausible mechanism by which phyto-oestrogen deprivation may exert several effects could be through a reduction in circulating $\mathrm{E}_{2}$ levels ${ }^{(3)}$. Our present results also showed decreased serum $\mathrm{E}_{2}$ concentrations in phyto-oestrogendeprived rats, which could not be prevented by dietary supplementation with whey.

One of the most remarkable alterations induced by phytooestrogen deprivation is the impairment of glucose homoeostasis - a hallmark of insulin resistance and diabetes $^{(3,35,38)}$. In the present study, the exacerbation of adiposity observed in PF-16-wk rats was concomitant with the appearance of diabetes and insulin resistance. This was reflected by high levels of fasting glucose combined with increased levels of circulating insulin and the consequent high HOMA index, in agreement with previous results ${ }^{(3)}$. The marked fat accretion observed in the last 6 weeks of treatment appeared to be essential in the onset of diabetes in phyto-oestrogendeprived male rats, and whey administration did not prevent the increase in fat depots or the high levels of fasting glucose. Whey proteins have been reported to improve glucose 
homoeostasis $^{(15-17)}$. Our results showed that, although whey administration did not reduce circulating glucose, circulating insulin levels were reduced when compared with PF-16-wk rats, which could be considered an improvement in insulin resistance. This result is in agreement with that found by Tong et al. ${ }^{(39)}$, who showed that administration of whey proteins for 8 weeks decreased circulating insulin in rats previously fed a high-fat diet, and attributed this effect to the high concentration of leucine in whey proteins. Moreover, Belobrajdic et al. ${ }^{(40)}$ reported that dietary whey reduces plasma insulin concentration compared with red meat, but only when provided along with a high-protein diet.

The present study demonstrated that whey administration reduces food intake and affects hypothalamic gene expression in obese phyto-oestrogen-deprived male rats. An increase in POMC expression was the main anorexigenic hypothalamic signal affected by dietary whey. On the other hand, 6 weeks of treatment was not enough to affect body weight or fat pad weights. Phyto-oestrogen deprivation modified endocrine homoeostasis, affecting total $\mathrm{T} 44$ and $\mathrm{E}_{2}$, and whey administration could not prevent these changes. High levels of circulating glucose were not prevented by whey administration; however, the reduction in fasting insulin is a promising result for a possible beneficial effect of whey with a longer treatment. Our results should encourage further studies considering the potential of whey proteins to reduce food intake and circulating insulin.

\section{Acknowledgements}

The authors thank Juan Grant and Juan C. Villarreal for their technical assistance and animal care. The authors also acknowledge Arla Foods Ingredients for the kind donation of Lacprodan 80 whey protein concentrate. The authors thank the Mathematics and Statistics Department of Facultad de Bioquímica y Ciencias Biológicas, Universidad Nacional del Litoral, for their kind assistance in statistical analysis.

This work was supported by the Universidad Nacional del Litoral CAI +D (grant nos 50120110100423LI and 50120110100167) and the Argentine National Agency for the Promotion of Science and Technology (APFCyT) (PICT grants nos 1715 and 0145). These funding agencies had no involvement in the study design; collection, analysis and interpretation of data; in the writing of the report; or in the decision to submit the article for publication.

The authors' contributions were as follows: M. F. A., E. H. L. and J. G. R. contributed to the experimental design; M. F. A., C. S., G. P. L. and G. C. performed the experiment and data analysis; M. F. A. and J. G. R. wrote the paper.

The authors declare that there are no conflicts of interest that could be perceived as prejudicing the impartiality of the study reported.

\section{References}

1. Christie DR, Grant J, Darnell BE, et al. (2010) Metabolic effects of soy supplementation in postmenopausal Caucasian and African American women: a randomized, placebocontrolled trial. Am J Obstet Gynecol 203, 153 e151-153 e159.

2. Liu ZM, Ho SC, Chen YM, et al. (2010) A mild favorable effect of soy protein with isoflavones on body composition - a 6-month double-blind randomized placebo-controlled trial among Chinese postmenopausal women. Int J Obes (Lond) 34, 309-318.

3. Andreoli MF, Stoker C, Rossetti MF, et al. (2015) Withdrawal of dietary phytoestrogens in adult male rats affects hypothalamic regulation of food intake, induces obesity and alters glucose metabolism. Mol Cell Endocrinol 401, 111-119.

4. Schwartz MW, Woods SC, Porte D Jr, et al. (2000) Central nervous system control of food intake. Nature 404, 661-671.

5. Valassi E, Scacchi M \& Cavagnini F (2008) Neuroendocrine control of food intake. Nutr Metab Cardiovasc Dis 18, 158-168.

6. Anderson GH, Aziz A \& Abou Samra R (2006) Physiology of food intake regulation: interaction with dietary components. Nestle Nutr Workshop Ser Pediatr Program 58, 133-143; discussion 143-135.

7. Luhovyy BL, Akhavan T \& Anderson GH (2007) Whey proteins in the regulation of food intake and satiety. $\mathrm{J} \mathrm{Am} \mathrm{Coll}$ Nutr 26, 704S-712S.

8. Chungchunlam SM, Henare SJ, Ganesh S, et al. (2014) Effect of whey protein and glycomacropeptide on measures of satiety in normal-weight adult women. Appetite 78, 172-178.

9. Tahavorgar A, Vafa M, Shidfar F, et al. (2014) Whey protein preloads are more beneficial than soy protein preloads in regulating appetite, calorie intake, anthropometry, and body composition of overweight and obese men. Nutr Res 34, 856-861.

10. MacKenzie-Shalders KL, Byrne NM, Slater GJ, et al. (2015) The effect of a whey protein supplement dose on satiety and food intake in resistance training athletes. Appetite 92, 178-184.

11. Pichon L, Potier M, Tome D, et al. (2008) High-protein diets containing different milk protein fractions differently influence energy intake and adiposity in the rat. Br J Nutr 99, 739-748.

12. Zhou J, Keenan MJ, Losso JN, et al. (2011) Dietary whey protein decreases food intake and body fat in rats. Obesity (Silver Spring) 19, 1568-1573.

13. Mobley CB, Fox CD, Ferguson BS, et al. (2015) Effects of protein type and composition on postprandial markers of skeletal muscle anabolism, adipose tissue lipolysis, and hypothalamic gene expression. J Int Soc Sports Nutr 12, 14.

14. Pezeshki A, Fahim A \& Chelikani PK (2015) Dietary whey and casein differentially affect energy balance, gut hormones, glucose metabolism, and taste preference in diet-induced obese rats. J Nutr 145, 2236-2244.

15. Nilsson M, Holst JJ \& Bjorck IM (2007) Metabolic effects of amino acid mixtures and whey protein in healthy subjects: studies using glucose-equivalent drinks. Am J Clin Nutr 85, 996-1004.

16. Pal S, Ellis V \& Dhaliwal S (2010) Effects of whey protein isolate on body composition, lipids, insulin and glucose in overweight and obese individuals. Br J Nutr 104, 716-723.

17. Shertzer HG, Woods SE, Krishan M, et al. (2011) Dietary whey protein lowers the risk for metabolic disease in mice fed a high-fat diet. J Nutr 141, 582-587.

18. Gunnerud U, Holst JJ, Ostman E, et al. (2012) The glycemic, insulinemic and plasma amino acid responses to equicarbohydrate milk meals, a pilot study of bovine and human milk. Nutr J 11, 83.

19. Gunnerud UJ, Ostman EM \& Bjorck IM (2013) Effects of whey proteins on glycaemia and insulinaemia to an oral glucose load in healthy adults; a dose-response study. Eur J Clin Nutr 67, 749-753.

20. Salehi A, Gunnerud U, Muhammed SJ, et al. (2012) The insulinogenic effect of whey protein is partially mediated by a direct effect of amino acids and GIP on beta-cells. Nutr Metab (Lond) 9, 48.

21. Reeves PG, Nielsen FH \& Fahey GC Jr (1993) AIN-93 purified diets for laboratory rodents: final report of the American Institute of Nutrition Ad Hoc Writing Committee on the reformulation of the AIN-76A rodent diet. J Nutr 123, 1939-1951. 
22. Institute of Laboratory Animal Resources - National Research Council (1996) Guide for the Care and Use of Laboratory Animals. Washington, DC: National Academies Press.

23. Paxinos G \& Watson C (2005) The Rat Brain in Stereotaxic Coordinates, 5th ed. New York: Elsevier Academic Press.

24. Pfaffl MW (2001) A new mathematical model for relative quantification in real-time RT-PCR. Nucleic Acids Res 29, e45.

25. Catalano PN, Bonaventura MM, Silveyra P, et al. (2005) GABA (B1) knockout mice reveal alterations in prolactin levels, gonadotropic axis, and reproductive function. Neuroendocrinology 82, 294-305.

26. Matthews DR, Hosker JP, Rudenski AS, et al. (1985) Homeostasis model assessment: insulin resistance and beta-cell function from fasting plasma glucose and insulin concentrations in man. Diabetologia 28, 412-419.

27. Barsh GS \& Schwartz MW (2002) Genetic approaches to studying energy balance: perception and integration. Nat Rev Genet 3, 589-600.

28. Brown NM \& Setchell KD (2001) Animal models impacted by phytoestrogens in commercial chow: implications for pathways influenced by hormones. Lab Invest 81, 735-747.

29. Astrp A, Raben A \& Geiker N (2015) The role of higher protein diets in weight control and obesity-related comorbidities. Int J Obes (Lond) 39, 721-726.

30. Hall WL, Millward DJ, Long SJ, et al. (2003) Casein and whey exert different effects on plasma amino acid profiles, gastrointestinal hormone secretion and appetite. Br J Nutr 89, 239-248.

31. Fromentin G, Darcel N, Chaumontet C, et al. (2012) Peripheral and central mechanisms involved in the control of food intake by dietary amino acids and proteins. Nutr Res Rev 25, 29-39.

32. Walzem RL, Dillard CJ \& German JB (2002) Whey components: millennia of evolution create functionalities for mammalian nutrition: what we know and what we may be overlooking. Crit Rev Food Sci Nutr 42, 353-375.

33. Ropelle ER, Pauli JR, Fernandes MF, et al. (2008) A central role for neuronal AMP-activated protein kinase (AMPK) and mammalian target of rapamycin (mTOR) in high-protein diet-induced weight loss. Diabetes 57, 594-605.

34. Ruhlen RL, Howdeshell KL, Mao J, et al. (2008) Low phytoestrogen levels in feed increase fetal serum estradiol resulting in the 'fetal estrogenization syndrome' and obesity in CD-1 mice. Environ Health Perspect 116, 322-328.

35. Cederroth CR \& Nef S (2009) Fetal programming of adult glucose homeostasis in mice. PLOS ONE 4, e7281.

36. Marini H, Polito F, Adamo EB, et al. (2012) Update on genistein and thyroid: an overall message of safety. Front Endocrinol (Lausanne) 3, 94.

37. Wright CS, Craddock A, Weinheimer-Haus EM, et al. (2016) Thyroid status, insulin sensitivity and glucose tolerance in overweight and obese adults before and after 36 weeks of whey protein supplementation and exercise training. Endocr Res 41, 103-109.

38. Cederroth CR, Vinciguerra M, Gjinovci A, et al. (2008) Dietary phytoestrogens activate AMP-activated protein kinase with improvement in lipid and glucose metabolism. Diabetes $\mathbf{5 7}$, $1176-1185$

39. Tong X, Li W, Xu JY, et al. (2014) Effects of whey protein and leucine supplementation on insulin resistance in non-obese insulin-resistant model rats. Nutrition 30, 1076-1080.

40. Belobrajdic DP, McIntosh GH \& Owens JA (2004) A highwhey-protein diet reduces body weight gain and alters insulin sensitivity relative to red meat in wistar rats. $J$ Nutr $\mathbf{1 3 4}$, $1454-1458$ 